JST 8 (1) (2019)
JURNAL SENI TARI
Thtt://iournal.unnes.ac.id/siu/index.php/ist

\title{
Pelestarian Tari Pesta Baratan di Kecamatan Kalinyamatan Kabupaten Jepara
}

\author{
Alfiyatun Najah ${ }^{1}$, Malarsih Malarsih ${ }^{2}$, \\ Jurusan Pendidikan Seni Drama Tari dan Musik, Fakultas Bahasa dan Seni, \\ Universitas Negeri Semarang, Indonesia.
}

\section{Info Artikel \\ Sejarah Artikel:}

Diterima : 29 Mei 2019

Disetujui : 22 Juni 2019

Dipublikasikan : 23 Juli 2019

Keyword: Pesta Baratan Dance; Form of Presentation; Preservation

\begin{abstract}
Abstrak
Penelitian ini bertujuan untuk mengetahui bentuk penyajian dan pelestarian Tari Pesta Baratan di Kecamatan Kalinyamatan Kabupaten Jepara. Penelitian ini menggunakan metode kualitatif dengan teknik pengumpulan data menggunakan observasi, wawancara, dan dokumentasi serta teknik keabsahan data diperiksa dengan metode triangulasi sumber. Penelitian menghasilkan data bahwa Tari Pesta Baratan dibagi menjadi tiga jenis yaitu penari impes/lampion, penari obor, dan penari tampah. Tari Pesta Baratan mempunyai gerak sederhana yang diperindah diambil dari gerakan sehari-hari pada masa dahulu, pada penari impes/lampion menceritakan jika menjelang ramadhan banyak yang berjualan impes/lampion di pinggir jalan, pada penari obor menceritakan pada jaman dahulu penerangan menggunakan obor, pada penari tampah menceritakan bahwa orang jaman dahulu sering menggunakan tampah yang diisi puli atau makan khas Jepara. Pelestarian Tari Pesta Baratan dilakukan dengan tiga cara yaitu: 1) perlindungan, dilakukan oleh Yayasan Lembayung dengan mengadakan tari Pesta Baratan setiap tahunnya dan telah diakui pemerintah Kabupaten Jepara dengan dimasukannya ke dalam kalender event Jepara; 2) pengembangan, dilakukan Yayasan Lembayung yaitu tidak hanya menggelar tari Pesta Baratan di Kota Jepara namun sampai ke Kota Blora untuk memperkenalkan dan mempromosikan kepada masyarakat luar Kota Jepara; 3) pemanfaatan, dilakukan oleh pemerintah Jepara menghasilkan Rekor MURI sebagai pembawa impes/lampion terbanyak serta menjadi peserta Art Kids International Festival di Kota Jepara.
\end{abstract}

\begin{abstract}
This study purposed to determine the form of presentation and preservation of Pesta Baratan dance in Kalinyamatan Subdistrict, Jepara Regency. This study used qualitative methods with data collection techniques using observation, interviews, and documentation and the validity of data techniques examined by source triangulation method. The research produced data that the Pesta Baratan Dance was divided into three types namely impes/lantern dancers, torch dancers, and tampah dancers. Pesta Baratan dance has a simple and beautiful movement taken from the daily movements of the past, the impes/lantern dancers told us that before Ramadan many people were selling impes/lanterns on the roadside, the torch dancers told in ancient times lighting using torches, on dancers tampah relates that ancient people often used tampah filled with Puli or Jepara special food. The preservation of Pesta Baratan dance is carried out in three ways, namely: 1) protection, is carried out by the Lembayung Foundation by holding a Pesta Baratan Dance every year and has been recognized by the Jepara Regency government by including it in the Jepara event calendar; 2) development, carried out by the Lembayung Foundation is not only to hold the Pesta Baratan Dance in Jepara City but to Blora City to introduce and promote to people outside of Jepara City; 3) utilization, carried out by the Jepara government resulted in a record of MURI as the largestcarrier impregnator/ lanternand became a participant in the Art Kids International Festival in Jepara City.
\end{abstract}




\section{PENDAHULUAN}

Kebudayaan merupakan sistem pengetahuan yang meliputi sistem ide atau gagasan yang terdapat dalam pikiran manusia sehingga dalam kehidupan sehari-hari, kebudayaan itu bersifat abstrak. Kebudayaan secara empirik, senantiasa dikaitkan dengan suatu kelompok manusia (masyarakat atau bangsa) yang mempunyai seperangkat nilai dan kepercayaan yang merujuk pada cita-cita tertentu (Rohidi, 2013:3).

Masyarakat dan kebudayaan adalah seperti dua sisi yang berbeda dalam satu keping mata uang, artinya bahwa manusia adalah sosok yang berwujud, sementara kebudayaan juga memiliki wujud-wujud kebendaan yang tidak bisa diraba-raba. Kebudayaan adalah sebuah proses kehidupan yang terus menerus menyertai kehidupan manusia (Sumaryono, 2011:20).

Kebudayaan menunjukkan kepada berbagai aspek kehidupan meliputi cara-cara berperilaku, kepercayaankepercayaan dan sikap-sikap, dan juga hasil dari kegiatan manusia yang khas untuk masyarakat atau kelompok penduduk tertentu. Keberadaan kebudayaan di suatu daerah memiliki ciri khas tersendiri sehingga dapat membedakannya dengan daerah lainnya. Hal ini mendorong setiap penduduknya melestarikan dan mengembangkan tradisi yang ada di daerahnya, sehingga mewujudkan salah satu unsur seni budaya adalah kesenian, menurut Umar Kayam dalam Soehardjo yang menyatakan bahwa ungkapan kreativitas dari kebudayaan yang berupa ekspresi gagasan ungkapan perasaan manusia dengan wujud berupa pola kelakuan yang menghasilkan karya bersifat estetis dan bermakna dengan cabang-cabangnya meliputi: seni rupa, seni suara, seni gerak dan seni drama atau teater (Soehardjo, 1990:7-11).

Kesenian merupakan bagian dari tradisi budaya masyarakat yang senantiasa hidup sebagai bentuk eskpresi pribadi maupun ekspresi kelompok masingmasing daerah memiliki karakter berbedabeda sebagai warisan nenek moyang, tidak terkecuali juga kesenian yang ada di Jepara.
Menurut Widayanti, kota Jepara merupakan kerajaan penting setelah diperintah oleh Ratu Kalinyamat karena telah berjasa menyingkirkan kolonian Belanda sebanyak dua kali dan berjasa membudayakan seni ukir yang menjadi identitas kota Jepara. Berkat jasa Ratu Kalinyamat, membuat masyarakat Jepara tidak pernah lupa dan mereka selalu mengadakan tradisi-tradisi yang berkaitan dengan cerita Ratu Kalinyamat. Tradisi yang telah dilakukan sejak nenek moyang hingga generasi ke generasi berikutnya. Ada banyak tradisi yang diadakan oleh kota Jepara, yaitu: Tradisi perang Obor, pesta Lomban, dan juga salah satunya pesta Baratan (Wawancara pada hari Rabu, 5 Maret 2018).

Kata "Baratan" berasal dari sebuah kata Bahasa Arab, yaitu baraah yang berarti keselamatan atau barakah yang berarti keberkahan. Sedangkan menurut K.H. Mudhofar Fatkhurrohman istilah Baratan berasal dari kata Baro'ah atau Bara'atan yang berarti berkah (Hisom, 1991:28). Tradisi pesta Baratan dilaksanakan setiap tanggal 15 Sya'ban (kalender Komariyah) atau 15 Ruwah (kalender Jawa) yang bertepatan dengan malam Nifsu Sa'ban. Kegiatan dipusatkan di Masjid Al Makmur Desa Kriyan Kecamatan Kalinyamatan (Wawancara dengan Widayanti pada tanggal Rabu, 2 Mei 2018).

Tradisi Baratan merupakan kegiatan sosial yang melibatkan seluruh warga masyarakat sebagai tradisi tahunan yang diadakan sebelum menjelang bulan Ramadhan sebagai kegiatan sosial yang melibatkan seluruh warga masyarakat dalam usaha bersama untuk memeriahkan malam Nifsu Sa'ban, memperingati ulang tahun Kota Jepara dan sekaligus mengenang wafatnya suami Ratu Kalinyamat, yaitu Sultan Handhirin yang telah dibunuh oleh Arya Panangsang.

Malam Nifsu Sa'ban berkaitan dengan pergantian buku catatan amal baik dan buruk, maka tradisi Baratan ini dapat pula dikatakan sebagai ajang evaluasi diri untuk memohon ampun dan berlombalomba untuk melakukan perbuatan yang baik, karena seharusnya manusia melakukan semua yang telah diperintahkan-Nya dan menjauhi apa 
yang dilarang-Nya. Setelah bulan ini masyarakat akan kedatangan bulan suci Ramadhan yang penuh ampunan dan berkah, oleh karena itu masyarakat sangat antusias dalam melaksanakannya. Di samping tujuan tersebut, masyarakat juga mempunyai tujuan lain yaitu ingin mendapat keberkahan, keselamatan dan ketentraman dari Allah SWT.

Acara pesta Baratan awalnya digelar pada tahun 2004 di Kecamatan Kalinyamatan Kabupaten Jepara oleh Lembayung Production dengan pementasan Tari Pesta Baratan yang menceritakan "ngalab berkah ing sasi arwah" yang artinya kita meminta berkah pada bulan Nifsu Sa'ban atau Ramadhan. Ketika sudah memasuki bulan Nifsu Sa'ban atau Ramadhan banyak penduduk Kalinyamat yang menjual impes/lampion, dari sinilah masyarakat mendapatkan berkah dari hasil penjualan impes/lampion. Tarian ini diciptakan oleh Eka Liza Nurdiana.

\section{Lembayung}

Production merupakan sebuah yayasan yang berdiri sendiri/independen yang fungsinya sebagai wadah inspirasi dan kreativitas pemuda-pemudi di Kecamatan Kalinyamatan yang didirikan dalam rangka melestarikan tradisi budaya termasuk salah satumya tari Pesta Baratan. Pada tahun 2004 Yayasan Lembayung mendapatkan penghargaan dari rekor MURI sebagai penyaji lampion terbanyak dalam tradisi Pesta Baratan. Tidak hanya itu, Yayasan Lembayung juga mengikuti Art Kids International Festival pada tanggal 14 sampai 16 September 2018.

Kabupaten Jepara memiliki beberapa tarian yaitu Tari Krida Jati, Tari Tayub, Tenun Troso dan Tari Pesta Baratan. Tari Pesta Baratan dibandingkan dengan tarian yang lain kurang dikenal di lingkungan masyarakat Jepara karena kurang disebarluaskan hanya di Kecamatan Kalinyamatan. Berdasarkan latar belakang yang ada peneliti ingin mengetahui lebih lanjut tentang "Pelestarian Tari Pesta Baratan dan Bentuk Pertunjukan Pesta Baratan".

\section{METODE}

Penelitian mengenai pelestarian Tari Pesta Baratan di Kecamatan Kalinyamatan Kabupaten Jepara menggunakan metode penelitian kualitatif dengan pendekatan deskriptif, karena peneliti mendeskripsikan dan menganalisis data secara objektif berdasarkan fakta nyata dan kemudian memaparkan secara deskriptif mengenai pelestarian Tari Pesta Baratan di Kecamatan Kalinyamatan Kabupaten Jepara.

Teknik pengumpulan data menggunakan observasi, wawancara, dan dokumentasi serta teknik keabsahan data diperiksa dengan metode triangulasi sumber.

Observasi dilakukan di Yayasan Lembayung yang beralamatkan di Desa Bakalan RT 10 RW 02 Kecamatan Kalinyamatan Kabupaten Jepara. Observasi pertama melakukan pengamatan pada lokasi, tempat latihan, dan basecamp. Observasi kedua melakukan pengamatan pada kostum, alat musik, alat make up, dan piagam atau prestasi yang pernah diraih. Selain itu peneliti juga melakukan pendokumentasian meliputi perekaman pada saat wawancara dan pengambilan foto saat proses latihan.

Wawancara kepada narasumber yang pertama yaitu Winahyu Widayati, S.Pd, selaku pimpinan Yayasan Lembayung yang berkaitan dengan sejarah Kabupaten Jepara, sejarah Tari Pesta Baratan, sejarah Yayasan Lembayung berlokasi di Yayasan Lembayung. Wawancara yang kedua dengan Eka Liza Nur Diana selaku pelatih dan koreografer Tari Pesta Baratan yang berkaitan dengan gerakan tari dan pola lantai Tari Pesta Baratan yang berlokasi di Yayasan Lembayung. Wawancara ketiga dengan Laila Febri Qodriyana selaku penari Tari Pesta Baratan yang berkaitan dengan gerakan tari dan pola lantai Tari Pesta Baratan yang berlokasi di Yayasan Lembayung.

peneliti $\begin{gathered}\text { Dokumentasi yang digunakan } \\ \text { mendapatkan data-data }\end{gathered}$ administrasi Yayasan Lembayung, datadata prestasi Yayasan Lembayung, fotofoto pelatihan Tari Pesta Baratan, fotofoto pertunjukan Tari Pesta Baratan, foto- 
foto kostum Tari Pesta Baratan, foto rias Tari Pesta Baratan.

Teknik analisis data adalah proses mencari dan menyusun secara sistematis data yang diperoleh dari hasil wawancara, catatan lapangan, dan dokumentasi dengan cara mengorganisasikan data ke dalam kategori, menjabarkan ke dalam kategori, menjabarkan ke dalam unit-unit, melakukan sintesa, menyusun ke dalam pola, memilih mana yang penting dan yang akan dipelajari, dan membuat kesimpulan sehingga mudah dipahami oleh diri sendiri maupun orang lain (Sugiyono 2010:244). Langkah-langkah yang dilakukan dalam analisis data adalah reduksi data, penyajian data, penarikan kesimpulan atau verifikasi.

Penelitian ini menggunakan triangulasi sumber, peneliti mengambil data dari beberapa sumber yaitu, Winahyu Widayanti selaku ketua Yayasan Lembayung, Eka Liza Nurdiana selaku koreografer, dan Laila Febri Qodriana selaku penari.

\section{HASIL DAN PEMBAHASAN}

\section{Gambaran Umum Kondisi Geografis dan Demografis Kecamatan Kalinyamatan}

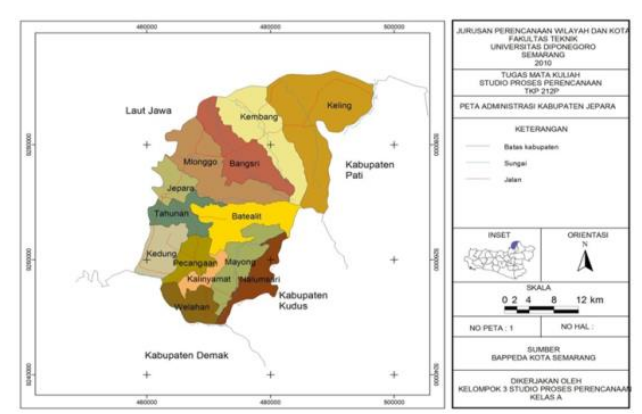

Gambar 1. Peta Kecamatan Kalinyamatan (Sumber : http://indonesia-

peta.blogspot.com/gambar-peta-kecamatan$\underline{\text { Kalinyamatan-jateng.htm/) }}$

Kecamatan Kalinyamatan terletak di sebelah Timur Ibukota Kabupaten Jepara. Batas sebelah Timur Kecamatan Kalinyamatan yaitu Kecamatan Mayong, batas sebelah Barat yaitu Kecamatan Mayong, sebelah Utara yaitu Kecamatan Pecangaan dan
Kecamatan Batealit, sebelah Selatan yaitu Kecamatan Welahan. Kecamatan Kalinyamatan dengan ketinggian antara $2 \mathrm{~m}$ sampai dengan $29 \mathrm{~m}$ dari permukaan Laut. Jarak dari Kecamatan kalinyamatan ke Ibukota Kabupaten Jepara 18km.

Kecamatan Kalinyamatan merupakan kecamatan yang ada di Kota Jepara dengan total 13.986 jiwa dengan jumlah desa ada 12 desa. Dari 12 desa yang ada di Kecamatan Kalinyamatan tidak semua penduduk pendukung Tari Pesta Baratan baik penari, pemusik, ataupun anggota Lembayung yang tinggal di Kecamatan Kalinyamatan hanya sebagian saja. Mayoritas mereka tinggal dari luar Kecamatan Kalinyamatan, tetapi masih tinggal di Kota Jepara.

\section{Sejarah Tari Pesta Baratan}

Tari Pesta Baratan merupakan salah satu tari tradisional yang berasal dari Kecamatan Kalinyamatan dan telah diakui oleh pemerintah Kabupaten Jepara dengan dimasukkannya Tari Pesta Baratan ke kalender event Jepara. Seperti yang disampaikan Eka Liza Nurdiana (27 Januari 2019):

$$
\text { "...Temanya ngalab }
$$

berkah ing sasi arwah, artinya kita meminta berkah pada Nifsu Sya'ban (Berkah dibulan Ramadhan), konsepnya diambil dari orang-orang dahulu yang sering menggunakan Impes/Lampion untuk penerangan pada malam hari..."

Ngalab berkah ing sasi arwah yang dimaksud yaitu ketika sudah memasuki bulan Nifsu Sa'ban atau Ramadhan banyak penduduk Kalinyamat yang menjual impes/lampion, dari sinilah masyarakat mendapatkan berkah dari hasil penjualan impes/lampion.

Tarian ini diciptakan oleh Eka Liza Nurdiana. Tari Pesta Baratan pertama kali diciptakan tahun 2004, tetapi tahun 2017 tarian ini dikreasikan atau dikembangkan. Properti yang digunakan dalam mendukung penyajian Tari Pesta Baratan yaitu impes/lampion, tampah yang di dalamnya ada puli makanan Jepara. Arti puli yaitu memaafkan dan obor sebagi penerangan. 
Proses penggarapannya mengambil gerakan yang lebih sederhana dikarenakan penarinya tidak murni penari yang sudah bisa, tetapi mayoritas penarinya pemula. Penciptaan Tari Pesta Baratan yaitu sebagai wisata budaya berbasis religi, agar penonton tidak hanya menonton orang jalan (arak-arakan), dan untuk mengembangkan sajiannya. Fungsi Tari Pesta Baratan sendiri sebagai pelengkap teatrikal Ratu Kalinyamatan. Untuk proses penciptaannya sangat singkat. Seperti yang disampaikan Eka Liza Nurdiana (27 Januari 2019)

"...Dengan waktu yang sangat singkat 2 Minggu, mengambil gerakan yang lebih sederhana dikarenakan penarinya tidak murni penari yang sudah biasa tetapi penari pemula, dan lancar sampai hari $H$, Tarian ini terinspirasi dari masa kecil pada saat bermain masa lalu dan gerakan diperindah ..."

Awal kemunculannya pun bermula dari perbincangan penduduk Kalinyamatan yang melihat fenomena lampu impas, setiap menjelang Nifsu Sya'ban banyak orang yang menjual lampu impes di pinggir jalan. Dari situlah mereka mendapatkan ide membuat Rekor MURI lampu lampion terbanyajk dengan teatrikal Ratu Kalinyamatan yang di dalamnya ada Tari Pesta Baratan.

Tari Pesta Baratan mulanya hanya dipentaskan 1 tahun sekali pada saat malam Nifsu Sya'ban saja karena sudah menjadi tradisi tahunan Pesta Baratan, tetapi sekarang sesuai dengan permintaan pemerintah Jepara. Seperti acara Pakudjembara yang dipentaskan di Blora, di alun-alun Jepara, maupun di rumah belajar Ilalang.

Anggota pendukung penyajian Tari Pesta Baratan tidak semua tinggal di Kecamatan Kalinyamatan, tetapi masih berdomisili Jepara. Penari dalam Tari Pesta Baratan rata-rata berusia 13 tahun sampai 25 tahun. Penarinya dibagi menjadi 3 jenis yaitu penari impes, penari obor, dan penari tampah.

\section{Profil Yayasan Lembayung}

Yayasan Lembayung adalah yayasan yang berdiri sendiri/independen yang fungsinya sebagai wadah inspirasi dan kreativitas pemuda-pemudi di Kecamatan Kalinyamatan yang didirikan dalam rangka melestarikan tradisi budaya termasuk salah satunya menyelenggarakan Tari Pesta Baratan.

Yayasan Lembayung beralamat di Desa Bakalan RT 10 RW 02 Kecamatan Kalinyamatan Kabupaten Jepara. Jumlah anggotanya ada 41 orang. Tidak semua anggota berdomisili di Kecamatan Kalinyamatan, tetapi masih di Kota Jepara. Pada tahun 2004 Lembayung Production mendapatkan penghargaan dari Rekor MURI sebagai penyaji lampion terbanyak dalam tradisi Pesta Baratan. Tidak hanya itu, Lembayung juga mengikuti Art Kids International Festival pada tanggal 14 sampai 16 September 2018.

\section{Bentuk Penyajian Tari Pesta Baratan di Kecamatan Kalinyamatan \\ Bentuk penyajian Tari Pesta} Baratan meliputi gerak, iringan, properti, tata rias, tata busana, tata cahaya, tata suara, pelaku, dan tempat pertunjukan.

\section{Gerak}

Gerak Tari Pesta Baratan berasal dari penggambaran orang-orang dahulu yang sering menggunakan obor untuk penerangan pada malam hari, serta tampah yang digunakan orang dulu untuk wadah Puli (makanan khas Jepara), Impes/lampion penggambaran orang yang berjualan impes/lampion di pinggir jalan pada menjelan bulan Ramadhan. Penciptanya sendiri terinsiprasi dari masa kecil pada saat bermain di masa lalu.

Diskripsi gerak Tari Pesta Baratan meliputi: 1) Srisig impes berupa gerakan berjalan melingkar dengan membawa 2 impes salah satu impes diangkat ke atas, 2) Lambaian impes berupa properti impes dimainkan ke atas bawah dengan tempo sedang, 3) Junjungan obor berupa kedua tangan memegang obor dengan loncat junjungan, 4) Duduk lambaian impes berupa tangan kanan dan kiri melambai ke kanan dan ke kiri secara bergantian, 5) Junjungan obor seperti memainkan obor ke kanan dan ke kiri sambil loncat junjungan, 6) Laku lambai berupa berjalan menggerakkan impes ke atas dan ke bawah dengan posisi tangan di depan, 7) 
Sebar puli berupa berjalan dengan gerakan seperti membagikan puli, 8) Lambaian tampah berupa tampah diletakkan di atas kepala dengan tangan melambai ke depan dan belakang, 9) Ayak tampah berupa tampah diletakkan di depan badan layaknya mengayak beras, 10) Lambaian ngisor berupa sikap duduk dengan tangan melambai ke depan dan ke belakang, 11) Sebar puli berupa penari menyebar dengan tampah di atas kepala dan tangan seperti membagikan makanan/puli.

\section{Iringan}

Penyajian tari Pesta Baratan tidak lepas dari musik pengiring. Musik pengiring tari Pesta Baratan menggunakan terdiri dari biola, rebana, botol.

Biola merupakan alat musik gesek yang sumber bunyinya dari dawai yang digesek. Biola terdiri dari 4 dawai yaitu G, D, A, dan E. Alat penggesek biola bernama bow, serabutnya terbuat dari ekor kuda. Tetapi di jaman yang modern seperti sekarang ini, tersedia juga bow yang terbuat dari sintetis nilon, karena kualitas yang bagus dan harga yang relatif lebih terjangkau. Sama halnya dengan biola, bow juga dalam perkembangannya banyak mengalami perubahan dari segi bahan, tekstur, dan bentuknya.

Rebana merupakan salah satu alat musik tradisional yang dipukul menggunakan tangan langsung. Bentuknya yang seperti marawis (alat musik pukul yang bentuknya semacam gendang berukuran kecil). Bentuknya yang pipih membuatnya mudah untuk dipegang menggunakan sebelah tangan dan tangan yang lain bisa untuk memukul.

Botol plastik merupakan tempat air mineral. Apabila sudah tidak ada air mineralnya digunakan untuk alat musik. Sebagai pengganti air mineral di dalam botol diisi beras, pasir atau kacang hijau lalu di kocok ke atas bawah sehingga dari gerakan beras, pasir atau kacang hijau tadi menghasilkan sebuah suara yang bisa dijadikan sebagai iringan tari.

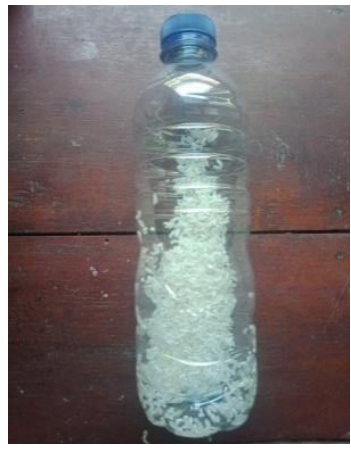

Gambar 2. Botol Plastik

(Sumber: Alfiyatun Najah, 2018)

\section{Properti}

Properti merupakan pelengkap pertunjukan yang dipakai oleh seorang penari saat pentas (Soedarsono dalam Gupita 2012: 4). Properti berfungsi sebagai elemen tari untuk menghidupkan tarian dan memberikan kesan yang mendalam bagi penikmat atau penonton.

Tari Pesta Baratan di dalam penyajiannya menggunakan properti impes atau lampion, obor dan tampah. Penggambaran fungsi impes atau lampion dan obor di dalam tarian Pesta Baratan sebagai penerangan, sedangkan tampah sebagai tempat puli atau makanan Jepara.

\section{Tata Rias}

Tata rias pada Tari Pesta Baratan yaitu rias korektif atau rias cantik. Rias korektif adalah rias panggung yang berusaha membuat wajah terlihat sempurna dengan menutupi kekurangan pada wajah dan menonjolkan kelebihan wajah.

Kriteria cantik pada rias korektif Tari Pesta Baratan adalah saat wajah terlihat segar saat penonton melihat penari di panggung. Kulit wajah terlihat mulus dan berwarna natural sesuai warna kulit asli penari karena diberi alas bedak, bedak tabur, dan bedak padat. Penonjolan bagian wajah agar cantik terlihat dari penambahan warna pada alis, kelopak mata, hidung, pipi, dan bibir. Warna alis coklat kehitam-hitaman dan tebal, kelopak mata diberi warna agar terlihat besar dan tajam. Hidung dibuat mancung dengan memberi shading warna coklat di pinggir hidung. Pipi diberi warna merah agar aura wajah berseri, segar dan manis. Bibir diberi warna merah untuk 
menyempurnakan wajah penari menjadi terlihat cantik.

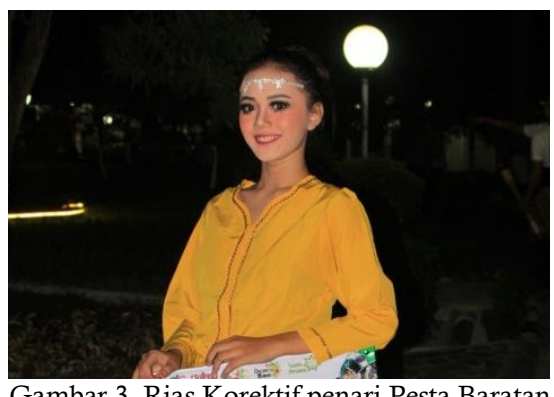

Gambar 3. Rias Korektif penari Pesta Baratan

(Sumber: Eka Liza Nurdiana, 2017)

\section{Tata Busana}

Masing-masing tokoh memiliki kostum yang berbeda. Berikut ini foto desain busana Tari Pesta Baratan.

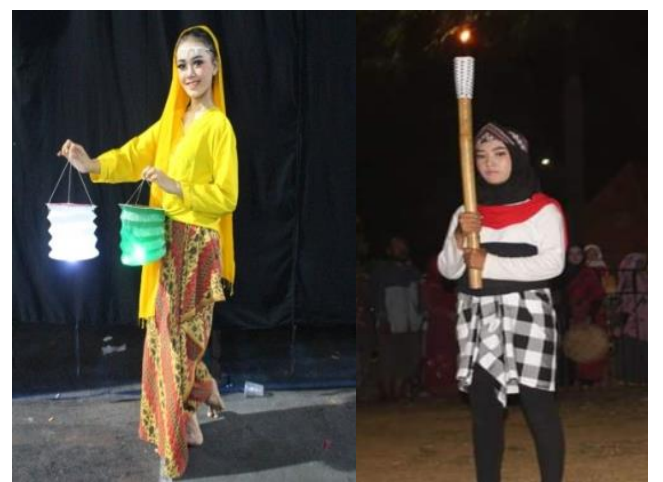

Gambar 4. Busana Penari Impes dan Penari Obor (Sumber: Eka Liza Nurdiana, 2017)

Busana yang digunakan dalam penyajian tari Pesta Baratan terdiri dari: jarik sebagai penutup kaki, selendang sebagai penutup kepala, kebaya sebagai penutup badan, iket kepala sebagai aksesoris kepala, baju polos sebagai penutup badan, kace sebagai aksesoris yang menutup dada, stagen sebagai pengencang agar jarik tidak lepas, leging panjang sebagai penutup kaki, manset sebagai penutup badan, kain bermotif kotak-kotak Bali sebagai penutup kaki, jilbab sebagai penutup rambut, dan kain troso sebagai penutup badan.

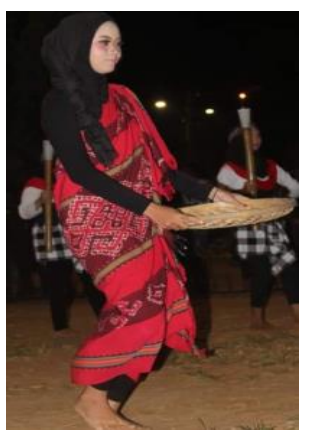

Gambar 5.Tata Busana Penari Tampah

(Sumber: Eka Liza Nurdiana, 2017)

\section{Tata Cahaya}

Sarana dan prasarana yang ideal bagi sebuah pertunjukan adalah bila gedung pertunjukan telah dilengkapi dengan peralatan yang menunjang penyelenggaraan pertunjukan, khususnya tata cahaya (Jazuli 2008:29). Tata pencahayaan pada Tari Pesta Baratan pada penyajiannya menggunakan tata pencahayaan general. Pencahayaan general di dalam sebuah pertunjukan tidak menggunakan lampu yang berwarnawarni, tetapi di dalam pertunjukan hanya menggunakan pencahayaan 1 warna saja.

\section{Tata Suara}

Tata suara adalah suatu teknik pengaturan peralatan suara atau bunyi pada suatu acara pertunjukan. Pengaturan tersebut meliputi pengaturan mikrofon, kabel-kabel, prosesor dan efek suara, pengaturan konsul mixer, kabel-kabel dan juga Audio Power amplifer dan speakerspeaker. Pertunjukan Tari Pesta Baratan menggunakan sound system dan speaker yang memiliki volume suara yang keras sehingga iringan musik dapat terdengar oleh para penari maupun penonton yang menyaksikan pertunjukan.

\section{Pelaku}

Pelaku sajian tari Pesta Baratan di Kecamatan Kalinyamatan Kabupaten Jepara terdiri dari: sutradara, penari, pemain musik, dan koreografer. Sutradara merupakan orang yang paling berperan penting, bertanggung jawab terhadap kelancaran pertunjukan. Tugas sutradara yaitu mengarahkan pemain agar sesuai dengan skenario yang dicapai. Sutradara 
bertanggung jawab terhadap kelancaran pertunjukan.

Penari Pesta Baratan ada 3 jenis: Penari Impes yang membawa impes/lampion. Penari obor membawa api dengan menggunakan bambu. Penari tampah membawa tampah yang diisi puli makanan khas Jepara.

Pemain musik meliputi: pemain biola, pemain rebana, dan pemain botol. Koreografer Tari Pesta Baratan bertugas sebagai pencipta tarian atau penata tari.

\section{Tempat}

Pertunjukan Tari Pesta Baratan bisa dilakukan di atas panggung, namun bisa juga dilakukan di aula gedung, atau di lapangan menurut event yang dilaksanakan. Namun biasanya tarian ini diselenggarakan di halaman kantor Kecamatan Kalinyamatan.

\section{Pelestarian Tari Pesta Baratan}

Tari Pesta Baratan merupakan salah satu tarian tradisi yang ada di kota Jepara. Tarian ini tidak banyak masyarakat yang tau. Untuk itu Yayasan Lembayung melakukan sebuah usaha pelestarian Tari Pesta Baratan agar dapat dikenal dan tidak punah. Seperti yang disampaikan Winahyu Widayanti (2 Mei 2018):

“... dengan menggelar rutin Tari Pesta Baratan setiap tahunnya agar tidak punah dan selalu diingat masyarakat menjelang Nisfu Sya'ban, terlebih anak-anak yang suka dengan impes atau lampion..."

Berdasarkan temuan di lapangan terkait dengan pelestarian Tari Pesta Baratan di Kecamatan Kalinyamatan mengindikasikan tiga kegiatan meliputi perlindungan, pengembangan, dan pemanfaatan.

\section{Perlindungan}

Perlindungan merupakan upaya dalam menjaga tarian miliknya agar tidak diambil dan diakui oleh daerah lain atau negara lain. Perlindungan dilakukan oleh Yayasan Lembayung untuk Tari Pesta Baratan dengan cara menyajikan Tari Pesta Baratan di dalam tradisi Pesta Baratan yang diadakan pada malam Nifsu
Sya'ban, agar dapat diakui oleh Kota Jepara. Yayasan Lembayung menghasilkan Rekor MURI dan sekarang Pemerintah Kota Jepara telah menjadikan Tari Pesta Baratan termasuk ke dalam salah satu tarian kota Jepara dan kini Tari Pesta Baratan masuk ke dalam kalender event di Kabupaten Jepara.

\section{Pengembangan}

Pengembangan merupakan usaha dalam meningkatkan kualitas tarian ataupun pertunjukan agar semakin baik dan dapat dinikmati oleh masyarakat luas. Pengembangan yang dilakukan Yayasan Lembayung pada Tari Pesta Baratan terletak pada kostum yang dulunya menggunakan kebaya berwarna warni dan jarik bermotif tidak sama sehingga terlihat tidak kompak tetapi sekarang menggunakan kebaya berwarna sama dan jarik bermotif sama sehingga terkesan lebih kompak. Yayasan Lembayung juga menggelar pertunjukan tidak hanya di Kota Jepara saja, namun juga sampai ke Blora dalam acara Pakudjembara. Pakudjembara adalah sebuah event gelar budaya yang diikuti 6 kota yang ada di Jawa Tengah yaitu Pati, Kudus, Demak, Jepara, Rembang dan Blora. Kegiatan ini merupakan salah satu ajang bagi Kota Jepara untuk memperkenalkan dan mempromosikan Tari Pesta Baratan sebagai tarian Kota Jepara kepada masyarakat luar Kota Jepara.

\section{Pemanfaatan}

Pemanfaatan yaitu upaya dalam pendayagunaan sesuatu yang dimiliki, salah satu tarian. Pemanfaatan Tari Pesta Baratan dilakukan oleh masyarakat Kecamatan Kalinyamatan sebagai sarana ekonomi karena dengan diadakan Tari Pesta Baratan penjualan impes/lampion semakin meningkat. Pemanfaatan Tari Pesta Baratan juga dimanfaatkan oleh pemerintah Kabupaten Jepara sebagai sarana hiburan melalui pementasan Tari Pesta Baratan pada malam Nisfu Sya'ban, tidak hanya itu Tari Pesta Baratan juga digunakan sebagai sarana komunikasi meliputi promosi pariwisata dan promosi Kota Jepara yang dilakukan di Blora pada event Pakudjembara, Tari Pesta Baratan juga dimanfaatkan untuk mengikuti event 
Art Kids International Festival yang dilaksanakan di Jepara.

\section{SIMPULAN}

Bentuk Penyajian Tari Pesta Baratan yang dikemas meliputi: gerak menggunakan properti impes atau lampion, obor dan tampah yang berisi puli atau makanan Jepara. Iringannya menggunakan biola, rebana, botol, dan kecrekan kayu yang diisi kacang hijau. Kostum yang dikenakan berbeda-beda tergantung peran yang dibawakan. Rias yang digunakan adalah rias korektif.

Pelestarian Tari Pesta Baratan dilakukan secara bersama-sama antara Yayasan Lembayung dengan pemerintah Kabupaten Jepara. Upaya pelestarian meliputi perlindungan, pengembangan, dan pemanfaatan. Kerjasama yang baik antara pelaku seni dan pemerintah telah membuat tarian ini mengalami eksistensi yang baik.

\section{DAFTAR PUSTAKA}

Gupita, Winduadi. 2012. Bentuk Pertunjukan Kesenian Jamailin di Desa Jatimulya Kecamatan Suradadi Kabupaten Tegal. Skripsi. Fakultas Bahasa dan Seni. Universitas Negeri Semarang.

Hisom, 1991. Ratu Kalinyamat Dan RA Kartini, Tanggung Jawab Moral Wanita Jepara. Jepara: PKK Kabupaten Dati II Jepara.

Jazuli, M. 2008. Pendidikan Seni Budaya Suplemen Pembelajaran Seni Tari. Semarang: UNNES Press.

Rohidi, Tjetjep Rohendi, 2013. Metodologi Penelitian Seni. Semarang : Prima Nusantara.

Soehardjo, 1990. Pendidikan Seni rupa. Jakarta: Departemen Pendidikan dan Kebudayaan.

Sumaryono, 2011. Antropologi Tari Dalam Perspektif Indonesia. Yogyakarta : ISI Yogyakarta 